\title{
Determinants and Risks Factors of Renal Failure in Patients with Heart Failure in Cardiology Department of CHU Sylvanus Olympio of Lomé (Togo)
}

\author{
Kossi Akomola Sabi ${ }^{*}$, Eyram Yoan Makafui Amekoudi', Soudougoua Baragou², \\ Komlan Georges Tona', Yaovi Afassinou' ${ }^{2}$, Machioude Pio², Béfa Noto-Kadou-Kaza1, \\ Badomta Dolaama1, Eugene Ametepe Attisso', Anani Amen Tevi', Mawusse Koffi Mensah', \\ Mindessou Murielle Schyldia Bonou-Selegbe ${ }^{3}$, Jaques Vigan ${ }^{3}$
}

${ }^{1}$ Department of Nephrology and Hemodialysis, CHU Sylvanus Olympio, Lomé, Togo

${ }^{2}$ Department of cardiology, CHU Sylvanus Olympio, Lomé, Togo

${ }^{3}$ Clinique de Néphrologie, CNHU, Cotonou, Bénin

Email: *kossi.sabi@gmail.com

How to cite this paper: Sabi, K.A., Amekoudi, E.Y.M., Baragou, S., Tona, K.G., Afassinou, Y., Pio, M., Noto-Kadou-Kaza, B., Dolaama, B., Attisso, E.A., Tevi, A.A., Mensah, M.K., Bonou-Selegbe, M.M.S. and Vigan, J. (2019) Determinants and Risks Factors of Renal Failure in Patients with Heart Failure in Cardiology Department of CHU Sylvanus Olympio of Lomé (Togo). Open Journal of Nephrology, 9, 65-76.

https://doi.org/10.4236/ojneph.2019.93008

Received: May 27, 2019

Accepted: September 1, 2019

Published: September 4, 2019

Copyright () 2019 by author(s) and Scientific Research Publishing Inc. This work is licensed under the Creative Commons Attribution International License (CC BY 4.0).

http://creativecommons.org/licenses/by/4.0/

(c) (i) Open Access

\begin{abstract}
Introduction: The morbidity and mortality of patients with heart failure are known to increase rapidly in the presence of renal insufficiency, which is usually the cause but may be a consequence. To organize better prevention of renal failure, we undertook this study to identify the determinants of renal failure in the population of patients with heart failure. Methodology: This was a retrospective descriptive and analytical study of heart failure (HF) cases hospitalized from January 1st to December 31st, 2016, over a period for twelve (12) months at CHU Sylvanus Olympio. Patients who performed cardiac Doppler ultrasound were included in our study. Renal failure was defined as eGFR (estimated glomerular filtration rate) less than 60 $\mathrm{ml} / \mathrm{min} / 1.73 \mathrm{~m}^{2}$. Multivariate logistic regression was performed to investigate associated factors. The dependent variable was DFG status: coded 1 if the GFR is less than $60 \mathrm{ml} / \mathrm{min}$ and 0 if not. Results: A total of 216 patients were included. The majority were female (54.17\%). The median age of patients was 53 years [IQI $=32-61$ years] with extremes of 15 and 96 years. $16.49 \%$ of patients had a GFR of less than $60 \mathrm{ml} / \mathrm{min}$. In multivariate analysis the average standard of living $(\mathrm{OR}=2.40, \mathrm{p}=0.0456)$, diabetes $(\mathrm{OR}=2.67, \mathrm{p}=0.0300)$, hypertension $(\mathrm{OR}=5.66, \mathrm{p}=0.0399)$, alcoholism $(\mathrm{OR}=4.00, \mathrm{p}=0.0063)$ were the main factors in the development of an RF/HF. Conclusion: The average standard of living, diabetes, hypertension, and chronic alcoholism are the determinants of renal failure in HF.
\end{abstract}




\section{Keywords}

Heart Failure, Renal Failure, Determinants, Togo

\section{Introduction}

Heart failure (HF) is a serious and frequent pathology whose evolution is enamelled of several complications with a risk of sudden death at all stages. It is an important public health problem because of its frequency, its impact on mortality and the significant medical and economic resources it absorbs [1] [2]. It is responsible for nearly 1 million hospitalizations in the United States and affects $1 \%$ to $2 \%$ of the population between 50 and 59 years [2]. In Togo, the work of Pio et al. [3] reveals that heart failure is the leading cause of hospitalization in cardiology at the Sylvanus Olympio University Hospital Center (CHU-SO). It is known that the morbidity and mortality of patients with heart failure increase rapidly in the presence of renal failure, which is usually the cause but may be a consequence [4]. In Togo, the prevalence of renal failure is estimated at $73.2 \%$ in nephrology consultation, with $11.6 \%$ of patients referred by cardiologists in heart failure [5]. In a context where health care is self-funded by the patient, kidney failure becomes inevitable and its treatment overwhelming for the patient. We therefore considered it necessary, to organize better prevention, to undertake this study to identify the determinants of renal failure in the population with heart failure.

\section{Patients and Methods}

The Cardiology Department of CHU-SO of Lomé which is the reference hospital of Togo served as a framework for our study. This was a descriptive and analytical retrospective study of hospitalized heart failure cases from January 1st to December 31st, 2016, over a twelve (12) month period. Patients with heart failure syndrome who performed a Doppler ultrasound scan were included in our study. Patients who did not have an HF or who had a clinical syndrome of HF and did not perform a cardiac Doppler ultrasound were not included in the study.

Questionnaire data were extracted from inpatient hospital registers during the study period. It was designed by the team of nephrologists of the department. It was first tested on a sample of 25 heart failure patients randomly selected to ensure that the questions and their answers were understood. The variables studied were of order:

- Sociodemographic: frequency, age, sex, place of residence, marital status, profession;

- Clinics: blood pressure (BP), body mass index (BMI), existence of diabetes, alcoholism, smoking, sedentary lifestyle, clinical signs of heart failure;

- Electrocardiographic: search for ischemia, ventricular hypertrophy, rhythm 
disorders;

- Biological: glomerular filtration rate (GFR) calculated according to the formula of the Renal Diseases Modification (MDRD), hemoglobin level, lipid balance disorder, proteinuria, hydroelectrolytic disorder, phosphocalcic disorders, infection to the human immunodeficiency virus;

- Cardiac Doppler ultrasound: the appearance of the myocardium and valves, type of cardiomyopathy, left ventricular ejection fraction (LVEF).

\section{Operational Definitions}

- Renal failure was defined as eGFR (estimated glomerular filtration rate) less than $60 \mathrm{ml} / \mathrm{min} / 1.73 \mathrm{~m}^{2}$ according to the simplified MDRD;

- Socio-economic groups were defined according to the SMIG (70\$) as follows: low level, for a monthly income below seventy dollars (70\$); average level, for a monthly income of between seventy and three hundred dollars (70 - 300\$); high level, for a monthly income exceeding three hundred dollars (300\$).

\section{Data processing}

The statistical analysis was performed with Studio software version 3.3.2. It consisted of a descriptive analysis, a comparative analysis and the logistic regression. It was a descriptive analysis of the population of heart failure patients with GFR $<60 \mathrm{ml} / \mathrm{min}$. The results were expressed in terms of size and percentage for the qualitative or median and interquartile range variables for the quantitative variables. All variables were cross-referenced to the degree of GFR. A comparative analysis was carried out to find a difference between the variables collected at inclusion, depending on whether the GFR is less than $60 \mathrm{ml} / \mathrm{min}$ or not. The statistical tests used were the Pearson Chi-square test or Fisher's exact test for qualitative variables and the Student's test for quantitative variables. The threshold of significance was set at 0.05 . Missing data were not considered in.

Multivariate logistic regression was performed to investigate associated factors. The dependent variable was GFR status: coded 1 if the GFR is less than 60 $\mathrm{ml} / \mathrm{min}$ and 0 if not. The explanatory variables were some sociodemographic, clinical and biological variables. The step-down procedure was used to select the final model. It consisted of including all the variables chosen in the initial model and then gradually removing the least significant variables. At each step, it was checked that there was no major confusion between the removed variable and those remaining in the model by checking the modifications of their Odds ratio (tolerated variation: 20\%) or even radical changes in their degrees of significance. The multivariate analysis made it possible to estimate the Adjusted Coast Ratio (RCa) and its 95\% confidence interval (CI) for each selected variable. After obtaining the final model, interactions were sought between the different variables of the final model by including interaction terms (product of the 2 variables concerned) in the model and verifying their non-significance. The adequacy of the model has been verified based on the $\mathrm{R}^{2}$ value.

\section{Ethical aspect}

All the medical information collected was anonymised before being transmitted to the investigations. The study was made according to the recommenda- 
tions of the ethics committee of the University of Lomé and in accordance with national and local regulations.

\section{Results}

A total of 216 patients with heart failure with a cardiac Doppler ultrasound were included. Of these patients, the majority were female $(54.17 \%)$. The median age of patients was 53 years [IQI = 32 - 61 years] with extremes of 15 and 96 years. Table 1 groups the other socio-demographic data of the population. Figure 1 shows the co-morbidities of the study population. The main comorbidities were hypertension in $62.7 \%$ of cases and obesity in $29.6 \%$ of cases. The median systolic blood pressure was $130 \mathrm{mmHg}$ [IIQ = $110-151 \mathrm{mmHg}$ ]. Of the 188 patients who achieved serum creatinine, 31 patients (16.49\%) had a GFR of less than $60 \mathrm{ml} / \mathrm{min} / 1.73 \mathrm{~m}^{2}$ and $2.13 \%$ of patients had a GFR of less than $15 \mathrm{ml} / \mathrm{min}$. The median proteinuria was $940 \mathrm{mg} /$ day [IIQ $=500-2350 \mathrm{mg} /$ day]. The prevalence of renal failure in the study population was estimated at $16.49 \%$. Male patients $(\mathrm{p}=0.0087)$, those older than 53 years $(\mathrm{p}=0.0254)$, patients with medium socioeconomic status $(\mathrm{p}=0.0313$ ) were more likely to renal failure. The comorbidities according to the GFR are presented in Table 1. Hypertensive patients ( $\mathrm{p}$ $=0.0005)$; diabetics $(\mathrm{p}=0.0016)$; sedentary $(\mathrm{p}=0.0011)$; antecedents of self-medication $(\mathrm{p}=0.0405)$, alcoholism ( $\mathrm{p}=0.0004)$; HIV infection ( $\mathrm{p}=$ $0.0017)$; with a hospital stay of more than 9 days $(\mathrm{p}=0.0002)$ had a high risk of having a GFR $<60 \mathrm{ml} / \mathrm{min} / 1.73 \mathrm{~m}^{2}$. Renal failure with $\mathrm{GFR}<60 \mathrm{ml} / \mathrm{min}$, was associated with impairment of left ventricular ejection fraction (LVEF) ( $\mathrm{p}=$ 0.0289), left ventricular hypertrophy $(\mathrm{LVH})(\mathrm{p}=0.0424)$, left atrial hypertrophy $(\mathrm{LAH})(\mathrm{p}=0.0248)$, ECG ischemia $(\mathrm{p}=0.0102)$ in our patients.

Table 2 presents the result of the univariate analyzes. A total of thirteen variables were associated with renal failure: males, age greater than 53 years, average socio-economic status, hypertension, diabetes, smoking, self-medication, alcoholism, lengths of hospital stay, impaired LVEF, LVH, LAH, ischemia. The risk of developing kidney failure is higher for males $(p=0.0107)$ in subjects older than 53 years $(\mathrm{p}=0.0289)$.

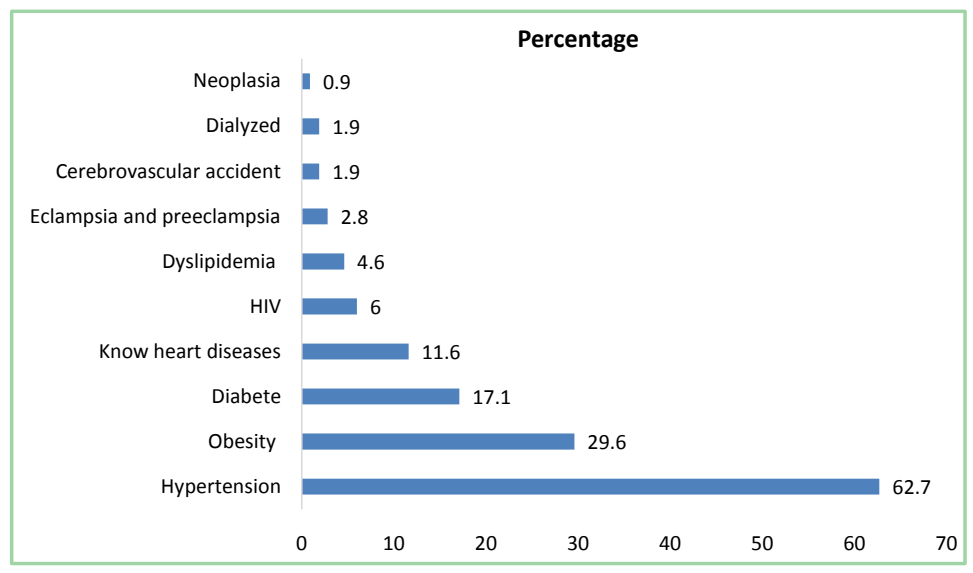

Figure 1. Distribution of patients by comorbidities related to heart failure. 
Table 1. Distribution of patients by comorbidities, lifestyle and socio-demographic data.

\begin{tabular}{|c|c|c|c|c|c|}
\hline & \multicolumn{5}{|c|}{ Univaried model } \\
\hline & $\mathrm{n} / \mathrm{N}$ & $\%$ & OR & CI à $95 \%$ & $\mathrm{P}$ \\
\hline Gender & & & & & 0.0107 \\
\hline Femal & $10 / 101$ & 9.9 & 1 & & \\
\hline Male & $21 / 87$ & 24.1 & 2.9 & {$[1.31-6.80]$} & \\
\hline \multicolumn{6}{|l|}{ Age (year) } \\
\hline$<53$ & $9 / 89$ & 10.11 & 1 & & \\
\hline$\geq 53$ & $22 / 99$ & 22.2 & 2.54 & {$[1.13-6.14]$} & 0.029 \\
\hline \multicolumn{6}{|c|}{ Socio-economic level } \\
\hline Hight & $16 / 128$ & 12.5 & 1 & & \\
\hline Average & $15 / 60$ & 25 & 2.33 & {$[1.06-5.14]$} & 0.034 \\
\hline \multicolumn{6}{|c|}{ Geographical area } \\
\hline Townsman & $23 / 158$ & 14.6 & 1 & & \\
\hline Rural & $8 / 30$ & 26.7 & 2.13 & {$[0.81-5.24]$} & 0.107 \\
\hline \multicolumn{6}{|l|}{ Obesity } \\
\hline No & $18 / 136$ & 13.2 & 1 & & \\
\hline Yes & $13 / 52$ & 25 & 2.18 & {$[0.97-4.85]$} & 0.055 \\
\hline
\end{tabular}

High blood pressure

No

Yes

Diabete

No

Yes

Smoking

No

Yes

Self-medication

No

Yes

Alcoholism

No

Yes

Sédentarity

No
Yes

Hospitalization duration

$$
<9 \text { days }
$$$$
>9 \text { days }
$$

$2 / 62$

$29 / 126$

$19 / 153$

$12 / 35$

$30 / 174$

$1 / 14$

$17 / 132$

$14 / 56$

$16 / 143$

$15 / 45$

$20 / 158$

$11 / 30$

$13 / 131$

$18 / 57$

$\begin{array}{cc}3.23 & 1 \\ 23 & 8.97\end{array}$

[2.57 - 56.75]

0.003

$\begin{array}{lcrr}12.4 & 1 & & \\ 34.3 & 3.68 & {[1.55-8.57]} & 0.003\end{array}$

.003 


\section{Continued}

\begin{tabular}{|c|c|c|c|c|c|}
\hline LEVF & & & & & \\
\hline Preserved & $5 / 62$ & 8.07 & 1 & & \\
\hline Weathered & $26 / 126$ & 20.6 & 2.96 & {$[1.16-9.14]$} & 0.035 \\
\hline \multicolumn{6}{|c|}{ Hemoglobin level } \\
\hline$<11 \mathrm{~g} / \mathrm{dl}$ & $12 / 75$ & 16 & 1 & & \\
\hline$\geq 11 \mathrm{~g} / \mathrm{dl}$ & $19 / 113$ & 16.8 & 1.06 & {$[0.48-2.39]$} & 0.883 \\
\hline \multicolumn{6}{|l|}{ LVH } \\
\hline No & $11 / 98$ & 11.2 & 1 & & \\
\hline Yes & $20 / 90$ & 22.2 & 2.26 & {$[1.03-5.18]$} & 0.046 \\
\hline \multicolumn{6}{|l|}{ LAH } \\
\hline No & $11 / 101$ & 10.9 & 1 & & \\
\hline Yes & $20 / 87$ & 23 & 2.44 & {$[1.11-5.61]$} & 0.029 \\
\hline \multicolumn{6}{|c|}{ Rythm disorder } \\
\hline No & $10 / 55$ & 18.2 & 1 & & \\
\hline Yes & $21 / 133$ & 15.8 & 0.84 & {$[0.37-2.00]$} & 0.688 \\
\hline \multicolumn{6}{|l|}{ Ischemia } \\
\hline No & $11 / 106$ & 10.4 & 1 & & \\
\hline Yes & $20 / 82$ & 24.4 & 2.78 & {$[1.28-6.40]$} & 0.012 \\
\hline
\end{tabular}

LVH: left ventricular hypertrophy; LAH: left atrial hypertrophy; LEVF: left ventricular ejection fraction; $\mathrm{N}$ $=$ total number of patients; $\mathrm{n}=$ effective of patient with $\mathrm{GFR}<60$; CI = confidence interval (95\%); OR = odds ratio.

Table 2. Effective and percentage of factors associated with renal failure in univaried model.

\begin{tabular}{|c|c|c|c|c|c|c|c|c|c|c|}
\hline & \multicolumn{3}{|c|}{ Effective } & \multicolumn{3}{|c|}{ GFR $<60$} & \multicolumn{3}{|c|}{ GFR $\geq 60$} & \multirow[t]{2}{*}{$\mathrm{p}$} \\
\hline & $\mathrm{N}=188$ & $\mathrm{n}$ & $\%$ & $\mathrm{~N}_{1}=31$ & $\mathrm{n}_{1}$ & $\%$ & $\mathrm{~N}_{2}=157$ & $\mathrm{n}_{2}$ & $\%$ & \\
\hline Gender & & & & & & & & & & 0.0087 \\
\hline Female & & 101 & 53.7 & & 10 & 32.3 & & 91 & 58 & \\
\hline Male & & 87 & 46.3 & & 21 & 67.7 & & 66 & 42 & \\
\hline Age (year) & & & & & & & & & & 0.0254 \\
\hline$<53$ & & 89 & 47.3 & & 9 & 29 & & 88 & 51 & \\
\hline$\geq 53$ & & 99 & 52.7 & & 22 & 71 & & 77 & 49.1 & \\
\hline Socio-economic level & & & & & & & & & & 0.0313 \\
\hline Hight & & 128 & 68.1 & & 16 & 51.6 & & 112 & 71.3 & \\
\hline Average & & 60 & 31.9 & & 15 & 48.4 & & 45 & 28.7 & \\
\hline Geographical area & & & & & & & & & & 0.1012 \\
\hline Townsman & & 158 & 84 & & 23 & 74.2 & & 135 & 86 & \\
\hline Rural & & 30 & 16 & & 8 & 25.8 & & 22 & 14 & \\
\hline
\end{tabular}




\section{Continued}

\begin{tabular}{|c|c|c|c|c|c|c|c|}
\hline Obesity & & & & & & & 0.0518 \\
\hline No & 136 & 72.3 & 18 & 58.1 & 118 & 75.2 & \\
\hline Yes & 52 & 27.7 & 13 & 41.9 & 39 & 24.8 & \\
\hline Diabete & & & & & & & 0.0016 \\
\hline No & 153 & 81.4 & 19 & 61.3 & 134 & 85.4 & \\
\hline Yes & 35 & 18.6 & 12 & 38.7 & 23 & 14.7 & \\
\hline High blood pressure & & & & & & & 0.0005 \\
\hline No & 62 & 33 & 2 & 6.45 & 60 & 38.2 & \\
\hline Yes & 126 & 67 & 29 & 93.6 & 97 & 61.8 & \\
\hline Smoking & & & & & & & 0.3272 \\
\hline No & 174 & 92.6 & 30 & 96.8 & 144 & 91.7 & \\
\hline Yes & 14 & 7.45 & 1 & 3.23 & 13 & 8.28 & \\
\hline Self-medication & & & & & & & 0.0405 \\
\hline No & 132 & 70.2 & 17 & 54.8 & 115 & 73.3 & \\
\hline Yes & 56 & 27.8 & 14 & 45.2 & 42 & 26.8 & \\
\hline Sedentary & & & & & & & 0.0011 \\
\hline No & 158 & 84 & 20 & 64.5 & 138 & 87.9 & \\
\hline Yes & 30 & 16 & 11 & 35.5 & 19 & 12.1 & \\
\hline Alcoholism & & & & & & & 0.0004 \\
\hline No & 143 & 76.1 & 16 & 51.6 & 127 & 80.9 & \\
\hline Yes & 45 & 23.9 & 15 & 48.4 & 30 & 19.1 & \\
\hline HIV & & & & & & & 0.0017 \\
\hline No & 147 & 90.7 & 23 & 85.2 & 124 & 91.9 & \\
\hline Yes & 9 & 5.56 & 0 & 0 & 9 & 6.67 & \\
\hline N/A & 6 & 3.7 & 4 & 14.8 & 2 & 1.48 & \\
\hline
\end{tabular}

$\mathrm{N}=$ total number of patients; N1 effective of patient with GFR $<60$; N2 = effective of patient with GFR $\geq$ 60

Table 3 represents the multivariate analysis after adjustment for socioeconomic level, diabetes, hypertension, alcohol, length of stay, ischemia, LVH, alcoholism, analysis shows that : mean standard of living (OR $=2.40,95 \%$ CI $[1.02$ - 5.10], $\mathrm{p}=0.0456)$, diabetes ( $\mathrm{OR}=2.67,95 \%$ CI $[1.31-4.68], \mathrm{p}=0.0300$, HTA $(\mathrm{OR}=5.66,95 \% \mathrm{CI}[1.30-10.20], \mathrm{p}=0.0399)$, alcoholism $(\mathrm{OR}=4.00,95 \% \mathrm{CI}$ [1.49 - 11.13], $\mathrm{p}=0.0063$ ) are the main factors in the development of renal failure associated with heart failure.

\section{Discussions}

This work really suffers from its retrospective character with the absence of data like proteinuria. Nonetheless, this kind of study is the first one in Togo and 
concerns a population with the main goal of isolating the factors that can be used for prevention. There are several risk factors for kidney disease: diabetes, hypertension, a family history of kidney disease, and congenital uropathies that are modifiable while aging and race are unmodifiable [6] [7]. Several studies have shown that Asians, South Asian, Pacific, African and Caribbean have a higher risk of chronic kidney disease [8]. The population of heart failure is a population at risk with a prevalence of renal failure at $16.49 \%$. This high prevalence found is like the result of Boully et al., who found $20 \%$ renal failure in a French heart failure population [9].

Table 3. Effective and percentage of factors associated with renal failure in analysis.

\begin{tabular}{|c|c|c|c|c|c|c|c|}
\hline & \multicolumn{4}{|c|}{ Initial model } & \multicolumn{3}{|c|}{ Final model } \\
\hline & $\mathrm{n} / \mathrm{N}$ & OR & CI à $95 \%$ & $p$ value & ORa & CI à $95 \%$ & $\mathbf{P}$ \\
\hline \multicolumn{8}{|l|}{ Gender } \\
\hline Femal & $10 / 101$ & 1 & & & & & \\
\hline Male & $21 / 87$ & 0.85 & {$[0.19-3.68]$} & 0.8233 & & & \\
\hline \multicolumn{8}{|c|}{ Socio-economic level } \\
\hline Hight & $16 / 128$ & 1 & & & 1 & & \\
\hline Average & $15 / 60$ & 2.59 & {$[0.73-9.54]$} & 0.1418 & 2.40 & {$[1.02-5.10]$} & 0.0456 \\
\hline \multicolumn{8}{|l|}{ Age (year) } \\
\hline$<53$ & $9 / 89$ & 1 & & & & & \\
\hline$\geq 53$ & $22 / 99$ & 1.98 & {$[0.59-7.03]$} & 0.2733 & & & \\
\hline \multicolumn{8}{|l|}{ Obesity } \\
\hline No & $18 / 136$ & 1 & & & & & \\
\hline Yes & $13 / 52$ & 0.91 & {$[0.28-2.85]$} & 0.8780 & & & \\
\hline \multicolumn{8}{|l|}{ Diabete } \\
\hline No & $19 / 153$ & 1 & & & 1 & & \\
\hline Yes & $12 / 35$ & 2.39 & {$[0.74-7.76]$} & 0.1431 & 2.67 & {$[1.31-4.68]$} & 0.0300 \\
\hline
\end{tabular}

High blood pressure

$\begin{array}{cccccccc}\text { No } & 2 / 62 & 1 & & 1 & & \\ \text { Yes } & 29 / 126 & 3.14 & {[0.56-26.68]} & 0.2292 & 5.66 & {[1.30-10.20]} & 0.0399\end{array}$

Self-medication

$\begin{array}{lcccc}\text { No } & 17 / 132 & 1 & & \\ \text { Yes } & 14 / 56 & 1.23 & {[0.37-3.99]} & 0.7291\end{array}$

Alcohol

$\begin{array}{lccccccc}\text { No } & 16 / 143 & 1 & & & & \\ \text { Yes } & 15 / 45 & 3.71 & {[1.14-13.25]} & 0.0337 & 4.00 & {[1.49-11.13]} & 0.0063\end{array}$

Geographical area

$\begin{array}{ccccc}\text { Townsman } & 23 / 158 & 1 & & \\ \text { Rural } & 8 / 30 & 1.99 & {[0.49-7.87]} & 0.3252\end{array}$




\section{Continued}

\begin{tabular}{|c|c|c|c|c|c|c|c|}
\hline \multicolumn{8}{|c|}{$\begin{array}{l}\text { Hospitalization } \\
\text { duration }\end{array}$} \\
\hline$<9$ & $13 / 131$ & 1 & & & & & \\
\hline$\geq 9$ & $18 / 57$ & 5.72 & [1.85 - 19.69] & 0.0034 & 5.92 & {$[2.10-18.54]$} & 0.0012 \\
\hline \multicolumn{8}{|c|}{ Sedentarity } \\
\hline No & $20 / 158$ & 1 & & & & & \\
\hline Yes & $11 / 30$ & 2.48 & [0.71 - 8.79] & 0.1532 & & & \\
\hline \multicolumn{8}{|c|}{ Ischemia } \\
\hline No & $11 / 106$ & 1 & & & 1 & & \\
\hline Yes & $20 / 82$ & 2.67 & [0.92 - 8.35] & 0.0762 & 2.27 & {$[1.10-4.54]$} & 0.0020 \\
\hline \multicolumn{8}{|c|}{ LVH } \\
\hline No & $11 / 98$ & 1 & & & 1 & & \\
\hline Yes & $20 / 90$ & 4.23 & [1.12 - 17.58] & 0.0378 & 4.50 & [1.57 - 10.53] & 0.0075 \\
\hline \multicolumn{8}{|c|}{ LAH } \\
\hline No & $11 / 101$ & 1 & & & & & \\
\hline Yes & $20 / 87$ & 1.97 & {$[0.66-6.22]$} & 0.2339 & & & \\
\hline
\end{tabular}

$\mathrm{N}=$ total number of patients; $\mathrm{n}=$ effective of patient with $\mathrm{GFR}<60 ; \mathrm{CI}=$ confidence interval $(95 \%) ; \mathrm{ORa}=$ adjusted odds ratio; LVH: left ventricular hypertrophy; LAH: left atrial hypertrophy.

We have identified in multivariate analysis, the average standard of living, diabetes, hypertension, chronic alcoholism as the determinants of kidney failure in heart failure.

Crew et al. in 2013 showed that low socioeconomic status can contribute to the development of the chronic kidney diseases (CKD) [10]. With a $2.4 \mathrm{RCa}$ the standard of living in our work appears as a very important determinant. This is explained by the fact that the health is still self-financed by the patient in Togo. There is no social security system and most patients have no health coverage. Heart failure is a heavy economic burden and patients become financially exhausted during treatment; this leads to complications of various kinds, which may be renal failure through cardiorenal syndrome type 1 which is a functional renal insufficiency. Susanne B, in a conceptual model, illustrated the relationship between the onset of renal disease chronic and poverty through, low birth weights, obesity, diabetes, hypertension and cardiovascular pathologies [8] [11] [12] [13].

High blood pressure is one of the major risk factors for the development and progression of renal failure [8]. With diabetes, it is a fatal duo and is the etiology of more than half of patients who have dialysis [14] [15]. In the literature, 50\% to $80 \%$ of patients have hypertension at the time of diagnosis of type 2 diabetes [14]. There is a strong link between diabetes and hypertension, which seems to be a two-way street. In a large cohort work done on cardiovascular risk factors in Hong Kong, only $42 \%$ of diabetic patients had normal BP [16]. The high preva- 
lence of hypertension in type 2 diabetics is explained by entangled pathophysiology of the two diseases [14]. Obesity has been identified as a risk factor for hypertension and diabetes. It is associated with an increase in blood mass and a decrease in peripheral resistance. However, the influence of obesity on BP goes through changes in blood flow and heart rate. In our study, $17.13 \%$ of patients were diabetic, $29.6 \%$ obese and $62.96 \%$ hypertensive. The economic burden of these two diseases is difficult to determine but it appears that controlling them would be a good way to slow the onset of kidney failure in the population with heart failure [12]. Indeed, among our patients, the risk of developing renal failure was high with diabetes $(\mathrm{RCa}=2.67)$ and much greater with hypertension $(\mathrm{RCa}=5.66)$.

Prenatal exposure to alcohol adversely affects kidney development, leading to a reduction in the number of nephrons [17] [18]. However, the mechanism by which alcohol acts to disrupt kidney development is little known. Several studies on the effects of alcohol on the heart muscle clearly demonstrate its deleterious effect [19] [20]. This involves the development of high blood pressure, the activation of complex inflammatory mechanisms, these mechanisms would probably explain the renal failure [19] [20]. The etiologies of heart failure in Togo are mainly hypertension, HIV, chronic alcoholism, pregnancy, degenerative and rheumatic valvulopathies, ischemic heart disease, tuberculous pericarditis and sickle cell disease [3] [21]. These main etiologies also appear to be the main determinants of renal failure.

Like any retrospective study, our study is skewed by its retrospective nature which justifies the lack of certain important data such as the elements that can enable us to classify renal insufficiency as acute (AKI) or chronic (CKD).

In addition, we relied on the estimation of glomerular filtration rate using the simplified MDRD equation. Although it is much better than the Cockcroft and Gault equation, because it is indexed on the surface of the body and not on the muscle mass, this MDRD equation is well known for its inaccuracy in extreme values of DFG, ie in the alterations severe or early renal function. The last consensus of KDIGO recommended the use of the CKD-EPI equation which in our context remains illusory because of the absence of international indexing of creatinine. Despite this, the MDRD equation holds its place because it has been validated in several reference works.

\section{Conclusion}

It appears that the average standard of living, diabetes, high blood pressure, chronic alcoholism were the determinants of renal failure in heart failure. The youth of the study population testify to the high frequency of heart failure in young people in developing countries and therefore the possibility of kidney failure. The renal failure is not only being the renal failure, a major comorbidity of heart failure, but also a two-way interaction between the heart and the kidney that is life-threatening. The control of these determinants will reduce the occur- 
rence of kidney disease in the population particularly of heart failure. This will require new studies that will identify the survival and mortality of patients with these comorbidities.

\section{Conflicts of Interest}

The authors declare no conflicts of interest regarding the publication of this paper.

\section{References}

[1] Schaufelberger, M., Swedberg, K., Köster, M., Rosén, M. and Rosengren, A. (2004) Decreasing One-Year Mortality and Hospitalization Rates for Heart Failure in Sweden: Data from the Swedish Hospital Discharge Registry 1988 to 2000. European Heart Journal, 25, 300-307. https://doi.org/10.1016/j.ehj.2003.12.012

[2] Frankenstein, L., Fröhlich, H. and Cleland, J.G. (2015) Multidisciplinary Approach for Patients Hospitalized with Heart Failure. Revista Española de Cardiología, 68, 885-891. https://doi.org/10.1016/j.rec.2015.05.008

[3] Pio, M., Goeh-Akue, E., Afassinou. Y., Baragou, S., Atta, B., Missihoun, E., et al. (2014) [Young Heart Failure: Epidemiological, Clinical and Etiological Aspects in the Teaching Hospital Sylvanus Olympio of Lome]. Annales de Cardiologie et d Angéiologie, 63, 240-244. https://doi.org/10.1016/j.ancard.2014.04.008

[4] Smith, G.L., Lichtman, J.H., Bracken, M.B., Shlipak, M.G., Phillips, C.O., DiCapua, P., et al. (2006) Renal Impairment and Outcomes in Heart Failure: Systematic Review and Meta-Analysis. Journal of the American College of Cardiology, 47, 1987-1996. https://doi.org/10.1016/j.jacc.2005.11.084

[5] Sabi, K.A., Noto-Kadou-Kaza, B., Amekoudi, Y.E., Tsevi, M.C. and Kossidze, K. Amedegnato, D. (2014) [Epidemiologic and Clinical Profile of Patients at Their First Consultation with a Nephrologist in Togo]. Médecine et Santé Tropicales, 24, 169-171. https://doi.org/10.1684/mst.2014.0318

[6] Ghonemy, T.A., Farag, S.E., Soliman, S.A., El-okely, A. and El-hendy, Y. (2016) Epidemiology and Risk Factors of Chronic Kidney Disease in the El-Sharkia Governorate, Egypt. Saudi Journal of Kidney Diseases and Transplantation, 27, 111-117. https://doi.org/10.4103/1319-2442.174137

[7] Torpy, J.M., Lynm, C. and Glass, R.M. (2007) Chronic Kidney Disease. The Journal of the American Medical Association, 298, Article ID: 1244.

https://doi.org/10.1001/jama.298.10.1244

[8] Sumaili, E.K., Krzesinski, J.M., Cohen, E.P. and Nseka, N.M. (2010) [Epidemiology of Chronic Kidney Disease in the Demovratic Republic of Congo: Review of Cross Selectional Studies from Kinshasa, the Capital]. Néphrologie \& Thérapeutique, 6, 232-239. https://doi.org/10.1016/j.nephro.2010.03.008

[9] Boully, C. and Hanon, O. (2015) [Heart failure and comorbidities]. Gériatrie et Psychologie Neuropsychiatrie du Vieillissement, 13, 13-22. https://doi.org/10.1684/pnv.2015.0544

[10] Nicholas, S.B., Kalantar-Zadeh, K. and Norris, K.C. (2013) Racial Disparities in Kidney Disease Outcomes. Seminars in Nephrology, 33, 409-415. https://doi.org/10.1016/j.semnephrol.2013.07.002

[11] Ronco, C., Cicoira, M. and McCullough, P.A. (2012) Cardiorenal Syndrome Type 1: Pathophysiological Crosstalk Leading to Combined Heart and Kidney Dysfunction in the Setting of Acutely Decompensated Heart Failure. Journal of the American 
College of Cardiology, 60, 1031-1042. https://doi.org/10.1016/j.jacc.2012.01.077

[12] Patzer, R.E. and McClellan, W.M. (2012) Influence of Race, Ethnicity and Socioeconomic Status on Kidney Disease. Nature Reviews Nephrology, 8, 533-541. https://doi.org/10.1038/nrneph.2012.117

[13] Nicholas, S.B., Kalantar-Zadeh, K. and Norris, K.C. (2015) Socioeconomic Disparities in Chronic Kidney Disease. Advances in Chronic Kidney Disease, 22, 6-15. https://doi.org/10.1053/j.ackd.2014.07.002

[14] Tatsumi, Y. and Ohkubo, T. (2017) Hypertension with Diabetes Mellitus: Significance from an Epidemiological Perspective for Japanese. Hypertension Research, 40, 795-806. https://doi.org/10.1038/hr.2017.67

[15] Bouattar, T., Ahid, S., Benasila, S., Mattous, M., Rhou, H., Ouzeddoun, N., et al. (2009) [The Factors for Progression of the Diabetic Nephropathy: Management and Evolution]. Néphrologie \& Thérapeutique, 5, 181-187.

https://doi.org/10.1016/j.nephro.2008.12.004

[16] Jiang, C.-Q., Thomas, G.N., Lam, T.H., Schooling, C.M., Zhang, W.-S., Lao, X.-Q., et al. (2006) Cohort Profile: The Guangzhou Biobank Cohort Study, a Guangzhou-Hong Kong-Birmingham Collaboration. International Journal of Epidemiology, 35, 844-852. https://doi.org/10.1093/ije/dyl131

[17] Gray, S.P., Cullen-McEwen, L.A., Bertram, J.F. and Moritz, K.M. (2012) Mechanism of Alcohol-Induced Impairment in Renal Development: Could It Be Reduced by Retinoic Acid? Clinical and Experimental Pharmacology and Physiology, 39, 807-813. https://doi.org/10.1111/j.1440-1681.2011.05597.x

[18] Das, S.K., McIntyre, H.D., Alati, R. and Al Mamun, A. (2019) Maternal Alcohol Consumption during Pregnancy and Its Association with Offspring Renal Function at 30 Years: Observation from a Birth Cohort Study. Nephrology, 24, 21-27. https://doi.org/10.1111/nep.13206

[19] Rodriguez, A., Chawla, K., Umoh, N.A., Cousins V.M., Ketegou, A., Reddy, M.G., et al. (2015) Alcohol and Apoptosis: Friends or Foes? Biomolecules, 5, 3193-3203. https://doi.org/10.3390/biom5043193

[20] Gardner, J.D. and Mouton, A.J. (2015) Alcohol Effects on Cardiac Function. Comprehensive Physiology, 5, 791-802. https://doi.org/10.1002/cphy.c140046

[21] Pio, M., Afassinou, Y., Pessinaba, S., Baragou, S., N'djao, J., Atta, B., et al. (2014) [Epidemiology and Etiology of Heart Failure in Lome]. Pan African Medical Journal, 18, 183. 